\title{
The impact of emerging technologies on work: a review of the evidence and implications for the human resource function
}

\section{[version 1; peer review: 2 approved, 1 approved with}

\section{reservations]}

\author{
Emma Parry (D), Valentina Battista (iD) \\ School of Management, Cranfield University, Cranfield, Bedfordshire, MK430AL, United Kingdom
}

V1 First published: 28 Jan 2019, 1:5
https://doi.org/10.12688/emeraldopenres.12907.1
Latest published: 28 Jan 2019, 1:5

https://doi.org/10.12688/emeraldopenres.12907.1

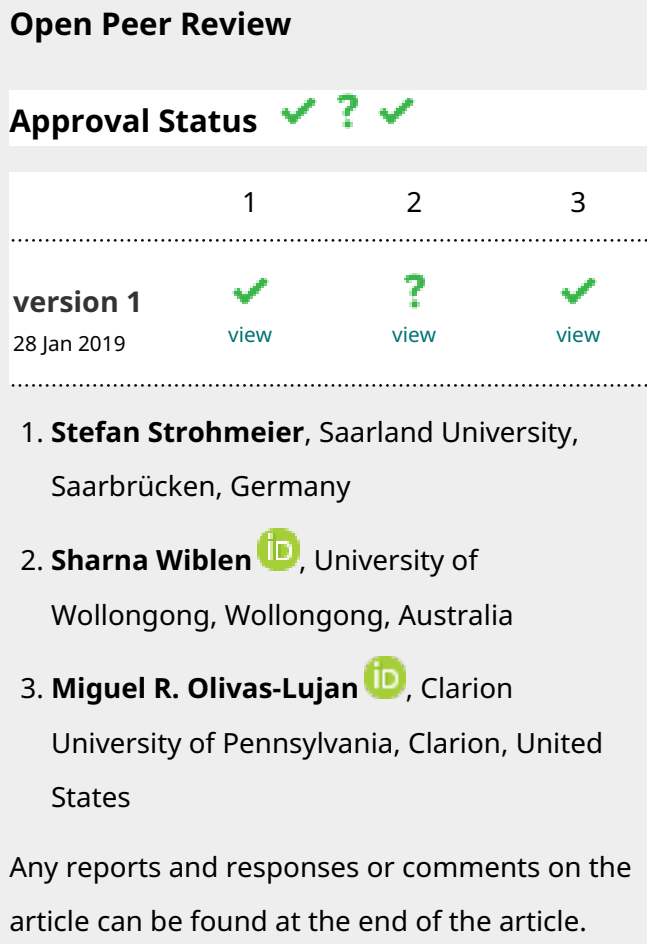

1. Stefan Strohmeier, Saarland University, Saarbrücken, Germany

2. Sharna Wiblen (D), University of Wollongong, Wollongong, Australia

3. Miguel R. Olivas-Lujan (iD), Clarion

University of Pennsylvania, Clarion, United

States

Any reports and responses or comments on the article can be found at the end of the article.

This article is included in the Responsible Management gateway. 
Corresponding author: Emma Parry (emma.parry@cranfield.ac.uk)

Author roles: Parry E: Conceptualization, Writing - Original Draft Preparation, Writing - Review \& Editing; Battista V: Conceptualization, Writing - Original Draft Preparation, Writing - Review \& Editing

Competing interests: No competing interests were disclosed.

Grant information: The authors declare that no grants were involved in supporting this work. However, this literature review did build on an earlier literature review funded by the Defence Human Capability Science and Technology Centre (DHCSTC).

Copyright: ( 2019 Parry E and Battista V. This is an open access article distributed under the terms of the Creative Commons Attribution License, which permits unrestricted use, distribution, and reproduction in any medium, provided the original work is properly cited.

How to cite this article: Parry $E$ and Battista $V$. The impact of emerging technologies on work: a review of the evidence and implications for the human resource function [version 1; peer review: 2 approved, 1 approved with reservations] Emerald Open Research 2019, 1:5 https://doi.org/10.12688/emeraldopenres.12907.1

First published: 28 Jan 2019, 1:5 https://doi.org/10.12688/emeraldopenres.12907.1 


\section{Introduction}

Over the last few years, we have seen a vast amount of attention paid to the impact of technological development on work, sometimes referred to as the changing world of work, particularly by popular media and consultants. Newspaper headlines such as "Robots will take our jobs. We'd better plan now before it's too late" (Elliott, 2018) have become commonplace. Some commentators also suggest that advances in technology will lead to changes in the workplace as dramatic as the collapse of the traditional employment relationship, the widespread use of artificial reality instead of travel and the replacement of humans with artificial intelligence (AI) and robotics. It is true to say that the most recent advancements in technology, such as AI, are having a dramatic effect on the workplace. Indeed, we are seeing rapid growth in the use of $\mathrm{AI}$ and robotics to automate simple and repetitive tasks such as factory work and many back-office duties; and to make complex decisions, such as medical diagnostics, quickly and more accurately via predictive algorithms. A recent study from Frey \& Osborne (2017) found that around 47\% of total employment is in the high-risk category - i.e., jobs expected to be automated over the next decade or two. Technological advancement is often associated with other changes within the world of work that might be facilitated by the technology itself, like for example, the disintegration of the traditional employment relationship to be replaced by gig economy work; an increased emphasis on flexibility and agility at work; and a new generation of employees with vastly different attitudes to the previous workforce. Amongst all of the propaganda surrounding the impact of technological advancement on the future of work, however, it remains unclear what the actual evidence base is in relation to this and what the role of the human resource (HR) function will be in supporting the organisation and its employees in navigating these changes.
The purpose of this study is, therefore, to take a more evidencebased approach to investigate this topic, via a structured review of the evidence. In doing this, the research aims to address the following research question: what is the published evidence relating to the impact of emerging technologies on work and what is the role of HR in relation to these changes?

Below we will present the methodology for this evidence review, followed by a summary of the results and conclusions from this study.

\section{Methods}

In order to address the question above, an analysis of published evidence relating to the impact of technology on work and people management was undertaken. Evidence reviews typically focus on peer-reviewed, academic papers. However, due to the time it takes to research and publish such outputs, and the speed of change in relation to technology, published information on technological advancement and its impact on work and people management tends to be slightly out of date. In order to address this limitation, we broadened our review to include the grey literature, and research undertaken by consultancies and similar bodies.

A comprehensive review of the existing evidence in relation to how technological advancement has/is changing the world of work; what technological trends are likely to directly affect work, the workplace or the workforce; and the role of HR in relation to these changes was therefore undertaken. To identify published evidence related to the above areas, a list of appropriate keywords and search strings was identified. These were grouped into the following six thematic areas: technology, work, future, HRM, working practices, and other trends (see Table 1).

Table 1. Keywords for review of published evidence.

\begin{tabular}{|c|c|c|c|c|c|}
\hline Technology & Work & Future & HRM & $\begin{array}{l}\text { Working } \\
\text { practices }\end{array}$ & Other trends \\
\hline Technological & Work & Future & Human Resource & Homeworking & Megatrends \\
\hline $\begin{array}{l}\text { Artificial } \\
\text { Intelligence (AI) }\end{array}$ & Workplace & 2030 & HRM & Remote Working & Globalisation \\
\hline Virtual Reality & Workforce & Advancement & HR Role & Flexible Work & Demographics \\
\hline Augmented Reality & Employment & New & HR Activity & Autonomy & $\begin{array}{l}\text { Multigenerational } \\
\text { workforce }\end{array}$ \\
\hline Automation & Work environment & Advances & HR Skills & & Gig economy \\
\hline Robotics & Work context & & HR Analytics & & \\
\hline Digital & Employees & & HR Professionals & & \\
\hline Online & Workers & & $\begin{array}{l}\text { People } \\
\text { Management }\end{array}$ & & \\
\hline e- & Labour & & $\begin{array}{l}\text { Talent } \\
\text { Management }\end{array}$ & & \\
\hline Wearables devices & Public sector & & & & \\
\hline \multirow[t]{2}{*}{ Sensors } & Government & & & & \\
\hline & Civil Service & & & & \\
\hline
\end{tabular}


A number of sources were used such as published studies in academic journals; and reports and research studies from non-academic bodies such as consultancies, think tanks and government bodies. These were identified via searches on online databases and the Internet (via ABI/INFORM Complete, ScienceDirect, Scopus, Web of Science, and Google) as well as via recommendations from experts in this field. Relying on both academic and non-academic databases is important given the nature of the subject matter, which is fed by various disciplines, including Psychology, Sociology, HRM, Organisational Behaviour, Information Systems, Computer Science, Innovation and Organisation Studies. Given the high speed of changes in technological advancement, we focused most of our attention on publications between 2010 and 2018 in order to gain the most up to date scenarios for the future of work.

Publications were analysed for relevance to our research question (i.e. did they focus on research pertaining to the research question?) and quality in relation to the research design. For example, studies were assessed in relation to whether they: were based in a comprehensive literature review; used rigorous and appropriate research methods; used a large enough and appropriate sample; employed appropriate analyses; drew conclusions based on the evidence. The research team reviewed the titles and abstracts of all the identified literature making an initial selection of 115 documents. Then, each document was critically examined for relevance to the literature review by a careful read of the document itself and evaluation of the contribution of each article to the three areas investigated. The final selection of this review comprised 51 documents.

\section{Findings}

The results identified a number of emerging technologies that are likely to have an impact on the future of work and therefore have implications for the HR function. First, digital platforms were shown to be used commonly within work and are central to online marketplaces such as Amazon or e-Bay and to labour market platforms such as Uber or Freelancer.com (Morgan, 2014; Zysman \& Kenney, 2018). Second, AI and machine learning were prominent within the published evidence and mostly applied for data analysis, finding patterns and making predictions (Government Office for Science, 2015). Third, robotics was seen as affecting employment as industrial robots have increasingly taken on routine tasks usually performed by manufacturing workers (Frey \& Osborne, 2017). Fourth, augmented and virtual reality (AR and VR) are demonstrated to be playing an increasingly significant role in industries such as healthcare, construction, oil and gas and aerospace (Higgins, 2017). Fifth, wearable devices are increasingly being employed in the workplace to improve employees' awareness about their personal wellness, to track employees' progress and plan measures to sustain their engagement (Kim et al., 2012; Moore \& Robinson, 2016; Moore \& Piwek, 2016; Wilson, 2013). Finally, blockchain was suggested as being used for transactions and information exchange that requires a high level of security (Wright, 2018; Yli-Huumo et al., 2016).
These emerging technologies will present a number of challenges for the HR function and for people management more broadly (Bondarouk \& Brewster, 2016; Marler \& Parry, 2016; Stone et al., 2015). Organisations will need to build a strategy for how they can most benefit from these technologies, for example to build efficiencies and improve the accuracy of decisionmaking, while also addressing any potentially negative impacts on employees. The role of the HR function in facilitating, or mitigating, the potential effects of emerging technologies on the workforce are presented briefly below.

\section{Automation and changing skills requirements}

Evidence suggests that there are enormous financial incentives for employers to increasingly automate their (currently human) processes (Markoff, 2011) and that advances in automation could dramatically change the nature of jobs available (PWC, 2017). Realistically, whether a task can be automated depends on the ability of coders to write a set of procedures that will improve the problem specification and account for every possible contingency (Frey \& Osbourne, 2017). Despite this limitation, automation is increasingly being used in areas that require the storing or access of information (Frey \& Osbourne, 2017), such as in fraud detection, medical diagnosis (Cohn, 2013; Wolcott, 2018) and law (Markoff, 2011). In addition, the automation of manual tasks is increasingly widespread, including tasks such as driving (Autor et al., 2003; Veres et al., 2011), cargo handling (Bloss, 2011) and mining (Frey \& Osbourne, 2017).

The role of HR practitioners in the process of automation is not clear from the evidence, but it would seem that they could play a key role in identifying tasks (and thus eventually roles) that could be automated. Perhaps more important however, is the HR function's role addressing the impact of job losses as a result of automation (Frey \& Osbourne, 2017; PWC, 2017). Not only should HR practitioners be central to supporting employees through a period of uncertainty while such decisions are made, they should also be responsible for considering how employees can be re-skilled or up-skilled in order to replace obsolete skills so that they can be retained in the workforce.

The evidence suggests that the type of knowledge, skills, and abilities required by organisations will change. For example, the need for routine cognitive and manual skills is decreasing, while the need for non-routine cognitive and manual skills has increased (Autor et al., 2003). Research suggests that organisations will need a workforce with increased skill variety, autonomy, and interdependence, as well as increased cognitive, creative, technical and social skills, (Liu \& Grusky, 2013; Wegman et al., 2018), to complement machines (MacCrory et al., 2014) and to perform the remaining tasks that are not automated (Makridakis, 2017). The HR function has a key role in ensuring the recruitment and development of these competencies as well as in designing leader development programmes that consider the new challenges related to managing employees in a modern work context and in coordinating humans and machines (Frey \& Osborne, 2017). 
Increased flexibility of time and place

There is considerable evidence that organisations are increasingly offering flexible working practices in order to meet employees' needs and to reduce costs associated with having a physical workplace (Berkery et al., 2017; de Menezes \& Kelliher, 2011; Stavrou et al., 2015). It is clear that developments in internet, and more recently mobile, technologies have increased the ability of individuals to work remotely and therefore out of usual office hours. However, it is also important to realise that technology is not the sole driver for an increase in flexible working as this has also been influenced by higher numbers of women in the workplace and by flexible pension arrangements (Atkinson, 2017). The management of flexible working policies, and creation of career and performance management systems that ensure that employees are not disadvantaged by working flexibly are undoubtedly the remit of the HR function. Indeed, research suggests that flexible working arrangements, while offering employees freedom about where and when they work, can also lead to work intensification (Kelliher \& Anderson, 2010).

The increase in remote working has led to a perceived decline in the physical workplace (Waber et al., 2014), although data would suggest that in most companies the take-up of home working is slow (Bevan, 2017). One reason for this might be the importance of face-to-face interaction, which has been shown to be necessary in order to sustain trustful relationships between employees (Forbes, 2013), maintain low stress levels (Chron, 2017) and improve employee performance (Waber et al., 2014). Indeed, as employees become increasingly dispersed, building relationships in the workplace will become a challenge. As virtual systems are becoming more frequently implemented within organisations, research focusing on the importance of social interactions in the workplace is increasing (Heaphy \& Dutton, 2008; Marlow et al., 2017; McGrath et al., 2017). For example, Heaphy \& Dutton (2008) suggested that social interactions at work, whether brief connections or enduring relationships, have physiological correlates and effects on the cardiovascular, immune, and neuroendocrine systems. They maintain that physiological resourcefulness built in positive social interactions shapes micro-organisational behaviour, such as engagement and work recovery, and that organisations shape employees by providing (or failing to provide) opportunities for these positive social interactions to occur. In a similar vein, McGrath et al. (2017) found that a greater level of social interaction predicts higher engagement in the workplace suggesting that such interactions act as a resource encouraging employees to immerse themselves in work. Moreover, their findings suggest that these positive effects do not end with the working day. To the contrary, on days when employees are engaged in their work, after work, they report greater participation in experiences that foster recovery. Therefore, organisations need to ensure employees find ways to interact. As a response to this need many organisations (e.g. Facebook) have led the development of shared spaces where employees can meet to work and interact.

\section{Employment arrangements}

The evidence suggested that the trend towards workers undertaking jobs using AI platforms via the gig economy and open talent economy is resulting in employment relations increasingly based on self-employment contracts, subcontracts, and various forms of 'gig-work' (Deloitte, 2013). Research suggests that almost 2.8 million workers in the UK are involved in the gig economy to some extent and that this is contributing to a decrease in demand for permanent employees, allowing organisations to reduce costs and increase their numerical flexibility (Berg, 2016). This in turn is said to be leading to precarious work conditions (Fleming, 2017; Moisander et al., 2018), the inability of individuals to be able to influence their working environment (CIPD, 2017) and a lack of institutional connectedness (Fitzgerald et al., 2012). In addition, the gig economy has been linked to growing economic insecurity, low productivity, diminished autonomy and increased levels of personal debt (Fleming, 2017).

HR practitioners therefore need to think about how the organisation might benefit from the flexibility that this approach might offer, while still ensuring that employees are not put at risk from a lack of support and employment security. It is important here that employers take a responsible, and longer term, approach to using these contracting arrangements, rather than focusing solely on short-term cost savings and flexibility.

\section{Effects on employee well being}

The above discussion suggests that employers need to consider a possible downside of the increased use of technology in the workplace. Indeed, research has proposed that the move to a workforce that is increasingly connected and contactable, along with the increase of global working, means that work is becoming nearer to 24/7 (Deloitte, 2016) and that the potential for employees to overwork (and thus damage their wellbeing) is increasing (Chron, 2016; Schlacter et al., 2018). Media coverage demonstrates that employees are concerned about this prospect. For example, employees from Google referred to connectivity as an "electronic leash" that damages their wellbeing (Independent, 2017), while other reports have linked increased connectivity with stress and burnout (The Guardian, 2016).

The HR function is central in the process of addressing such concerns as policies relating to employee wellbeing are to a large degree their responsibility. Indeed, some companies such as Daimler have introduced policies to encourage employees to disconnect outside of working hours (HR Magazine, 2017). However, it is difficult to enforce such ideas, and especially to balance the need for choice of when and where to work with the risk of overwork.

\section{The impact of emerging technologies on HRM}

The above examples suggest a role for the HR function in navigating the changes to work, the workplace and the workforce that are driven by technological advancement. However, it is important to also note that emerging technologies have been shown to also influence the way that organisations undertake their HR activities. The principal HR functions of attracting, selecting, developing, motivating and retaining talented employees in organisations (Stone et al., 2015) remain important, but potentially require different approaches in the future world of work (Holland \& Bardoel, 2016). For example, as reported by 
Davenport et al., (2010) we see companies adopting sophisticated data collection technology and analytics to improve methods of attracting and retaining talent, thus confirming the idea that technology is transforming the way that HR processes are managed, especially in relation to collecting and using data. Using interactive technologies can support line managers and HR professionals to enhance interactions and communication with their employees. In general, technology can provide new opportunities for HR. We have already seen that technology often increases efficiency in delivering services, decreases the administrative-related work, and allows HR to contribute to the strategic direction of organisations (Bondarouk \& Brewster, 2016; Stone et al., 2015). As Marler \& Parry (2016) suggest, the technology enabled shift from being primarily administratively oriented to being more strategically oriented, and the increasing availability of data might re-structure decision making processes creating new opportunities for HR people to be involved in "complex, judgment-oriented and professionally demanding tasks and responsibilities" (p. 2234). Emerging technologies might allow the further progression of this trend by, for example, allowing real-time monitoring of employee and workplace data via sensors and decision-making via complex algorithms (Bondarouk \& Brewster, 2016). At its most drastic, the increase in automation and rise in self-employment and the gig economy might result in a significantly smaller permanent workforce, meaning that the role of HR will be fundamentally changed.

\section{Conclusions and implications}

The findings of the evidence review and above discussion suggest that emerging technologies such as AI, robotics, VR and AR, digital technologies, wearables and blockchain have the potential to affect work and employees significantly. The degree and speed of this impact depends to a large extent on developments in the technologies themselves and the willingness of organisations to adopt them. This review also indicates that the HR function has a key role to play in helping employees to navigate the changes to the world of work particularly in relation to skills development, work organisation and mental health. While the key activities involved in HRM - to support managers in employees in going about their daily work (CEB, 2018) - are unlikely to change, the role of the HR function may become even more important as both the potential benefits and risks of emerging technologies for employees develop. Whether the HR function can successfully undertake this role depends upon their own skills development and their own understanding of technologies and their implications. Jesuthasan (2017) suggests that sustaining digital engagement in the future workplace will become a key part of the HR role. We would go beyond that statement and propose that actually the role of the HR function is also to develop and support employees in order to ensure their growth and wellbeing, as well as the sustainability of the organisation, against the backdrop of this technological advancement.

\section{Data availability}

There is no primary data associated with this article. All references are included in the reference list for this paper.

\section{Grant information}

The authors declare that no grants were involved in supporting this work. However, this literature review did build on an earlier literature review funded by the Defence Human Capability Science and Technology Centre (DHCSTC).
Atkinson K: The alpha effect: why the civil service will soon need more parttime roles. Institute for Employment Studies. 2017. Reference Source

Autor DH, Levy F, Murnane RJ: The skill content of recent technological change: An empirical exploration. Q J Econ. 2003; 118(4): 1279-1333. Publisher Full Text

Berg J: Income security in the on-demand economy: Findings and policy lessons from a survey of crowdworkers. Comparative Labor Law and Policy Journal. 2016; 37: 543.

Reference Source

Berkery E, Morley MJ, Tiernan S, et al.: On the uptake of flexible working arrangements and the association with human resource and organizational performance outcomes. Eur Manag Rev. 2017; 14(2): 165-183.

Publisher Full Text

Bevan S: Is there a mental health 'time-bomb' ticking away in the public sector? Institute for Employment Studies. 2017.

Reference Source

Bloss R: Mobile hospital robots cure numerous logistic needs. Ind Robot. 2011; 38(6): 567-571.

Publisher Full Text

Bondarouk T, Brewster C: Conceptualising the future of HRM and technology research. Int J Hum Resour Man. 2016; 27(21): 2652-2671.

Publisher Full Text

CEB: The CEO 20 Pulse on the Future of Work. Benchmark Report, Gartner Inc. (CEB). 2018.

Reference Source
Chron: The disadvantages of being connected to work 24/7. 2016.

Reference Source

Chron: Challenges faced by human resource managers because of technical changes. 2017.

Reference Source

CIPD: Power dynamics in work and employment relationships: the capacity for employee influence. Research Report, Chartered Institute of Personnel and Development.

2017.

Reference Source

Cohn J: The robot will see you now. The Atlantic online. 2013; accessed 7 March 2018.

Reference Source

Davenport TH, Harris J, Shapiro J: Competing on talent analytics. Harv Bus Rev 2010; 88(10): 52-58, 150.

PubMed Abstract

Deloitte: The Open Talent Economy', Resetting horizons: Global human capital trends reports. 2013.

Reference Source

Deloitte: Digital workplace and culture: How digital technologies are changing the workforce and how enterprises can adapt and evolve. 2016.

Reference Source

de Menezes LM, Kelliher C: Flexible working and performance: A systematic review of the evidence for a business case. Int J Manag Rev. 2011;13(4):

$452-474$

Publisher Full Text

Elliott L: Robots will take our jobs. We'd better plan now before it's too late. The 
Guardian. 2018.

Reference Source

Fitzgerald I, Hardy J, Martinez LM: The Internet, employment and Polish migrant workers: communication, activism and competition in the new organisational spaces. New Tech Work Employ. 2012; 27(2): 93-105.

Publisher Full Text

Fleming P: The Human Capital Hoax: Work, Debt and Insecurity in the Era of Uberization. Organ Stud. 2017; 38(5): 691-709.

Publisher Full Text

Frey $\mathrm{CB}$, Osborne MA: The future of employment: How susceptible are jobs to computerisation? Technol Forecast Soc. 2017; 114: 254-280.

Publisher Full Text

Forbes: Back to the future with face-to-face technology. 2013.

Reference Source

Government Office for Science: Artificial intelligence: opportunities and

Implications for the future of decision-making, Report. 2015

Reference Source

Guardian: French workers win legal right to avoid checking work email out-ofhours. 2016.

Reference Source

Heaphy ED, Dutton JE: Positive Social Interactions and The Human Body at Work: Linking Organizations and Physiology. Acad Manage Rev. 2008; 33(1): 137-162.

Publisher Full Text

Higgins V: Augmented \& virtual reality: The future of work, not just play. Prof Saf. 2017; 62(6): 86-87.

Reference Source

Holland P, Bardoel A: The impact of technology on work in the twenty-fist century: exploring the smart and dark side. Int J Hum Resour Man. 2016; 27(21): 2579-2581.

Publisher Full Text

HR Magazine: The future of recruitment. 2017.

Reference Source

Independent: Electronic leash: How the office email is taking over our lives. 2017. Reference Source

Jesuthasan R: HR's new role: rethinking and enabling digital engagement

Strategic HR Review. 2017; 16(2): 60-65.

Publisher Full Text

Kelliher C, Anderson D: Doing more with less? Flexible working practices and the intensification of work. Hum Relat. 2010; 63(1): 83-106.

Publisher Full Text

Kim T, McFee E, Olguin D, et al:: Sociometric badges: Using sensor technology to capture new forms of collaboration. J Organ Behav. 2012; 33: 412-427. Publisher Full Text

Liu Y, Grusky DB: The payoff to skill in the third industrial revolution. Am J Sociol. 2013; 118(5): 1330-1374.

Publisher Full Text

MacCrory F, Westerman G, Alhammadi Y, et al.: Racing with and against the machine: Changes in occupational skill composition in an era of rapid

technological advance. Thirty-fifth International Conference on Information Systems. Auckland. 2014

Reference Source

Makridakis S: The forthcoming Artificial Intelligence (AI) revolution: Its impact on society and firms. Futures. 2017; 90: 46-60.

Publisher Full Text

Markoff J: Armies of expensive lawyers replaced by cheaper software. New York Times, online. 2011.

Reference Source

Marler JH, Parry E: Human resource management, strategic involvement and e-HRM technology. Int J Hum Resour Man. 2016; 27(19): 2233-2253.

Publisher Full Text
Marlow SL, Lacerenza CN, Salas E: Communication in virtual teams: conceptual framework and research agenda. Hum Resour Manage Rev. 2017; 27(4): 575-589.

Publisher Full Text

McGrath E, Cooper-Thomas HD, Garrosa E, et al:: Rested, friendly, and engaged: The role of daily positive collegial interactions at work. J Organ Behav. 2017; 38: 1213-1226.

Publisher Full Text

Moisander J, Groß C, Eräranta K: Mechanisms of biopower and neoliberal governmentality in precarious work: Mobilizing the dependent self-employed as independent business owners. Hum Relat. 2018; 71(3): 375-398.

Publisher Full Text

Morgan J: The future of work. Wiley, Hoboken: New Jersey. 2014. Reference Source

Moore $\mathrm{P}$, Piwek L: Regulating wellbeing in the brave new quantified workplace. Empl Relat. 2016; 39(3): 308-316.

Publisher Full Text

Moore P, Robinson A: The quantified self: What counts in the neoliberal workplace. New Media Soc. 2016; 18(11): 2774-2792.

Publisher Full Text

PwC: Workforce of the future: The competing forces shaping 2030. Technical Report, PwC. 2017.

Reference Source

Schlacter A, Mcdowall A, Cropley A, et al.: Voluntary work-related technology use during non-work time: A narrative synthesis of empirical research and research agenda. Int J Manag Rev. 2018; 20(4): 825-846.

Publisher Full Text

Stavrou ET, Parry E, Anderson D: Nonstandard work arrangements and configurations of firm and societal systems. Int J Hum Resour Man. 2015; 26(19): 2412-2433.

Publisher Full Text

Stone DL, Deadrick DL, Lukaszewski KM, et al.: The influence of technology on the future of human resource management. Hum Resour Manage Rev. 2015;

25(2): 216-231.

Publisher Full Text

Veres SM, Molnar L, Lincoln NK, et al:: Autonomous vehicle control systems - a review of decision making. Proceedings of the Institution of Mechanical Engineers, Part I: Journal of Systems and Control Engineering. 2011; 225(2): 155-195. Publisher Full Text

Waber B, Magnolfi J, Lindsay G: Workspaces that move people. Harv Bus Rev. 2014; 92(10): 68-77, 121.

PubMed Abstract

Wegman LA, Hoffman BJ, Carter NT, et al.: Placing Job Characteristics in Context: Cross-Temporal Meta-Analysis of Changes in Job Characteristics Since 1975. J Manage. 2018; 44(1): 352-386.

Publisher Full Text

Wilson HJ: Wearable in the workplace. Harv Bus Rev. 2013; 91(9): 23-25. Reference Source

Wolcott RC: How automation will change work, purpose, and meaning. Harv Bus Rev. 2018; accessed 7 March 2018.

Reference Source

Wright AD: Top 6 HR Technology Trends for 2018. 2018.

Reference Source

Yli-Huumo J, Ko D, Choi S, et al:: Where Is Current Research on Blockchain Technology?-A Systematic Review. PLoS One. 2016; 11(10): e0163477. PubMed Abstract | Publisher Full Text | Free Full Text

Zysman J, Kenney M: The next phase in the digital revolution: Intelligent tools, platforms, growth, employment. Commun ACM. 2018; 61(2): 54-63.

Publisher Full Text 


\section{Open Peer Review}

\section{Current Peer Review Status:}

\section{Version 1}

Reviewer Report 02 April 2019

https://doi.org/10.21956/emeraldopenres.13973.r26316

(C) 2019 Olivas-Lujan M. This is an open access peer review report distributed under the terms of the Creative Commons Attribution License, which permits unrestricted use, distribution, and reproduction in any medium, provided the original work is properly cited.

\section{Miguel R. Olivas-Lujan}

Department of Management and Marketing, Clarion University of Pennsylvania, Clarion, PA, United States

I believe that this article represents a very clever (second) use of all the work involved in the comprehensive literature review carried out for an earlier project. I applaud the authors for finding a creative way to capitalize on the significant amount of effort invested in that work. I cannot disagree with most of the points made in this article, but I have a few suggestions to hopefully improve this contribution.

Within the Methods section, I recommend defining "the gray literature" in specific ways (preferably through a published reference, but this is not necessary). The last paragraph of the same section mentions "three areas investigated," without specifically mentioning them. My guess is that these three areas are the ones mentioned in the second paragraph, namely: how technology is changing work, what trends are likely to affect work, and HR roles in relation to these changes. My suggestion is to be explicit about "the three areas investigated."

For the Findings section, I would add to the sentence on blockchain that "privacy" is not a strength for blockchain applications (at least not at the time of this review). A high level of security in the form of immutability is the major strength of this emerging technology, but privacy is not, because of the need to keep replicas of the blockchain database for independent verification (Olivas-Lujan, 2018 ${ }^{1}$ ).

Overall, I found the article well-written, with compelling arguments based on recent, informed publications. I believe it offers a valuable contribution to the HR innovations literature and look forward to reading its final version.

\section{References}

1. Olivas-Luján MR: Blockchains in e-HRM: Hit or Hype?. 7th International e-HRM Conference. 2018. Reference Source

Is the work clearly and accurately presented and does it cite the current literature? 
Yes

Is the study design appropriate and is the work technically sound?

Yes

Are sufficient details of methods and analysis provided to allow replication by others? Yes

If applicable, is the statistical analysis and its interpretation appropriate?

Not applicable

Are all the source data underlying the results available to ensure full reproducibility? Yes

Are the conclusions drawn adequately supported by the results? Yes

Is the argument information presented in such a way that it can be understood by a nonacademic audience?

Yes

Does the piece present solutions to actual real world challenges?

Yes

Is real-world evidence provided to support any conclusions made?

Yes

Could any solutions being offered be effectively implemented in practice?

Yes

Competing Interests: No competing interests were disclosed.

Reviewer Expertise: $\mathrm{HRM}, \mathrm{OB}, \mathrm{HRIS}$.

I confirm that I have read this submission and believe that I have an appropriate level of expertise to confirm that it is of an acceptable scientific standard.

Reviewer Report 13 March 2019

https://doi.org/10.21956/emeraldopenres.13973.r26319

(c) 2019 Wiblen S. This is an open access peer review report distributed under the terms of the Creative Commons Attribution License, which permits unrestricted use, distribution, and reproduction in any medium, provided the original work is properly cited.

Sharna Wiblen 
Sydney Business School, University of Wollongong, Wollongong, NSW, Australia

I thank the authors for the opportunity to review this paper and wish to commend them for their endeavours to engage with a complex, but timely, topic as organisations seek to explore the challenges and opportunities associated with implementing technological innovations in an increasingly digital and interconnected world.

I offer the following feedback as mechanisms to further enhance the rigour and contributions of the paper:

1. Consider revising your Introduction to better articulate the context of your paper and state why we should be interested in learning more about the potential influence of emerging technologies on how we "work" and on the HR function. Positioning your paper within discussions about the 4th Industrial Revolution may be useful. As you know, technologicalbased change is not a new phenomenon. What is new, however, is that these new emerging technologies are able to not only automate defined processes, but there is the potential for certain technologies to be able to act as subjects - that is machine learning and AI may be able to make decisions. Be clear about what's new and different about technology today? What do these technologies promise to do? Discussion of how this era of change differs from those previously experienced can help to negate any potential assertions that your paper offers nothing "new". Make sure you also talk about how the notion of "work" is changing in your introduction. You note that "It is true to say that the most recent advancements in technology, such as AI, are having a dramatic effect on the workplace" what are these dramatic effects and again how are they changing work in ways that are different from previous ways? Support these assertions with wider examples to allow the reader to appreciate the complexity of change.

2. Given that your paper is about the intersection between technology and "HR", I think that explicit discussion of relevant HR theories and concepts would further enhance your introduction. If technology is to change the way HR works and contributes to organisations, then we should reflect on what the role of HR today is - debates about HR being the keeper of the process, data or strategic business partner may prove useful. There is also an extensive body of work showing that technology decreases, rather than enhances the role and impact of HR in operational and strategic processes. Will we see a larger or smaller role for HR? What do the above technology vendors say about the potential impact of their technology on the HR function?

3. Please elaborate on your Methods and more specifically how did you arrive at your "themes"? I appreciate that you narrowed the literature down to 51 documents, but how did you analyse and categorise these 51 documents to get to the themes presented in your Findings? How did you analyse the papers for references to technology and HR? Did all the papers talk about HR specifically? If the paper dealt only with technology then how did you decide what the role of HR is to these changes? Greater detail would help address any questions about methodological rigour. Maybe a table outlining the different "themes" may clarify the findings.

4. Be mindful of the way that you present your ideas. In parts of the paper the wording used infers that technological change is a given and that innovations "will" influence how we work and "will" require a role for HR. Technology is part of a larger complex system and 
the influence of technology will not be experienced equally. Some organisations, some HR functions and some individuals will experience this change in different ways. Qualifying statements such as "potential", "desired", "promoted" may help avoid positivistic inferences.

Other minor feedback points:

Support "Some commentators" on page 3 with references.

Replace "propaganda" with "rhetoric". Technology vendors sell a vision and offer promises but I would debate that they publish and promote propaganda.

Consider separating the research questions into 2 distinct questions. Discourses and rhetoric about the technology; influence and implications for HR (not impact as "impact" implies positivistic outcomes).

Clarify what you mean by "grey literature" as I'm unfamiliar with this term and way to categorise texts.

Be mindful about the references included. Given your study examines 51 documents, I would expect numerous references for each theme.

Remove reference to "mental health" on page 6 as you talk about employee well-being. References to this new concept seem to appear as an additional discussion point rather than afford a conclusion.

Include further details to explain how technology may change the role of HR. For example, on page 6 you note "At its most dramatic, the increase in automation and rise in selfemployment and the gig economy might result in a significantly smaller permanent workforce, meaning that the role of HR will be fundamentally changed" - please explain how? Do you have a case study or example to draw upon to show how each of these technological factors has changed the way HR operates?

Is the work clearly and accurately presented and does it cite the current literature? Yes

Is the study design appropriate and is the work technically sound? Yes

Are sufficient details of methods and analysis provided to allow replication by others? Yes

If applicable, is the statistical analysis and its interpretation appropriate? Not applicable

Are all the source data underlying the results available to ensure full reproducibility? Yes

Are the conclusions drawn adequately supported by the results? 
Yes

Is the argument information presented in such a way that it can be understood by a nonacademic audience?

Yes

Does the piece present solutions to actual real world challenges?

Yes

Is real-world evidence provided to support any conclusions made?

Yes

Could any solutions being offered be effectively implemented in practice?

Yes

Competing Interests: No competing interests were disclosed.

Reviewer Expertise: HR technology; electronic human resource management; Digiatalised talent management;

I confirm that I have read this submission and believe that I have an appropriate level of expertise to confirm that it is of an acceptable scientific standard, however I have significant reservations, as outlined above.

Reviewer Report 27 February 2019

https://doi.org/10.21956/emeraldopenres.13973.r26317

(C) 2019 Strohmeier S. This is an open access peer review report distributed under the terms of the Creative Commons Attribution License, which permits unrestricted use, distribution, and reproduction in any medium, provided the original work is properly cited.

\section{Stefan Strohmeier}

Saarland University, Saarbrücken, Germany

Research on the consequences of technological developments on human work is a) highly important since severe changes are to be expected and b) highly convoluted since numerous, heterogeneous and often contradictory consequences are assumed. Thus, the current contribution constitutes a timely and highly required overview on research on the impact of technological developments ("digitalization") on human work. It is the merit of the authors to identify relevant aspects of this research topic and to summarize central findings in an easily accessible way. Initially, the categorization of central consequence areas (Automation and changing skills requirements; Increased flexibility of time and place; Employment arrangements; Effects on employee well-being) is useful and maps the core areas of the current discussion. Expected consequences in these areas are summarized briefly and concisely. Major consequences for HRM are derived. In sum, readers get a quick, intelligible and systematic overview of the field. 
I would like to suggest a major, a medium and a minor improvement - hoping that the authors will assume them as constructive suggestions.

The major point refers to the "technological determinism" that, in my view, implicitly underlies larger parts of the paper. As potential differences in consequences are mentioned sometimes, impacts of technologies are frequently presented as if there were only one direction of change. This overlooks the fact that digital technologies offer potentials, which can be used in different directions. This depends on the intentions of the employing organizations and refers to a position that might be called "organizational voluntarism" (Strohmeier, 200911). The same base technology, such as augmented reality or robotics, thus can induce very different and even clearly contradictory consequences depending on the kind of its usage. Considering this position might offer explicitly different advantages: firstly, it offers an explicit and (from my perspective) more adequate conceptualization of technological consequences. Secondly, it allows explaining and explicitly considering different (and even contradictory) findings and assumptions in literature. For instance, based on the seminal study of Frey \& Osborne $\left(2017^{2}\right)$ the paper expects (dramatic) job losses; yet, there are also studies that expect even (slight) job gains due to technological developments (e.g., Federal Ministry of Labour and Social Affairs $\left(2015^{3}\right)$ ). Thirdly, the possibilities and necessities for action on the side of HRM can be conceptualized more adequately. What HR (as well as general management) needs to do is to identify proactively and exploit purposefully the (often extremely) broad potentials of new technologies to design work adequately, rather than reactively cope with fixed uni-directional (since causal) consequences.

A related medium point refers to enlarging the considered literature. However, the aim of it should not and need not be a "complete anthology" of available contributions. Instead, a few contributions should be added to uncover the respective range of expected consequences. To use again the above example of employment consequences: beside the studies that expect dramatic job losses, also the studies with deviating results should be considered. This will inform readers about consequences, on which literature agrees, and about consequences, on which literature does not agree.

As a final minor point, you could enlarge and concretize the method section and uncover further aspects such as the number, sources, topics etc. of studies you have found.

\section{References}

1. Strohmeier S: Concepts of e-HRM consequences: a categorisation, review and suggestion. The International Journal of Human Resource Management. 2009; 20 (3): 528-543 Publisher Full Text 2. Frey C, Osborne M: The future of employment: How susceptible are jobs to computerisation?. Technological Forecasting and Social Change. 2017; 114: 254-280 Publisher Full Text 3. Federal Ministry of Labour and Social Affairs: Transfer of the study from Frey/Osborne (2013) to Germany. Final Report.2015.

\section{Is the work clearly and accurately presented and does it cite the current literature? Yes}

\section{Is the study design appropriate and is the work technically sound?}


Are sufficient details of methods and analysis provided to allow replication by others? Yes

If applicable, is the statistical analysis and its interpretation appropriate?

Not applicable

Are all the source data underlying the results available to ensure full reproducibility?

No source data required

Are the conclusions drawn adequately supported by the results?

Yes

Is the argument information presented in such a way that it can be understood by a nonacademic audience?

Yes

Does the piece present solutions to actual real world challenges?

Yes

Is real-world evidence provided to support any conclusions made?

Yes

Could any solutions being offered be effectively implemented in practice?

Yes

Competing Interests: No competing interests were disclosed.

Reviewer Expertise: Digitalization (of HRM); HR technologies, e-HRM, HRIS

I confirm that I have read this submission and believe that I have an appropriate level of expertise to confirm that it is of an acceptable scientific standard. 